\title{
Organophosphorus pesticide residues in vegetables and soil samples from alau dam and gongulong agricultural areas, Borno State, Nigeria
}

\author{
J. C. Akan, L. Jafiya, Z. Mohammed, F. I. Abdulrahman \\ Department of Chemistry, University of Maiduguri, P.M.B 1069, Maiduguri, Borno State, Nigeria
}

Email address:

joechemakan@yahoo.com (J. C.Akan)

To cite this article:

J. C. Akan, L. Jafiya, Z. Mohammed, F. I. Abdulrahman. Organophosphorus Pesticide Residues in Vegetable and Soil Samples from Alau Dam and Gongulong Agricultural Areas, Borno State, Nigeria. International Journal of Environmental Monitoring and Analysis. Vol. 1, No. 2, 2013, pp. 58-64. doi: 10.11648/j.ijema.20130102.14

\begin{abstract}
The Concentrations of organophosphorus pesticide residues (dichlorvos, diazinon, chlorpyrifos, and fenitrothion) were determine in some vegetables (spinach, lettuce, cabbage, tomato and onion) and soil samples from different depths within Alau Dam and Gongulong agricultural areas in Borno State, Nigeria. Samples collection and preparation were carried out using standard procedures. The concentrations of all the pesticides in the vegetables and soil samples were determined using GC/MS SHIMADZU (GC-17A) equipped with electron capture detector (ECD). The highest concentrations of diclorvos, diazinon, chlorpiryfos and fenithrothion in the Alau Dam and Gongulong agricultural areas were observed in the leaf of tomato, while the lowest concentrations were observed in the root of spinach. The concentrations of all the pesticides in the soil samples were observed to be higher at a depth of $21-30 \mathrm{~cm}$, while the lowest concentrations were observed at a depth of $0-10 \mathrm{~cm}$. The concentrations of all the organophosphorus pesticides in the vegetables and soil samples from the two agricultural areas were observed to be at alarming levels, much higher than the maximum residue limits (MRLs) and acceptable daily intake values (ADIs) set for vegetables and soil by the Cordex 2009 (WHO and FAO). The occurrence of pesticides in the vegetables and soil samples is a major threat to human that depends on these vegetables as food. Hence, the need for continuous monitoring is recommended so as to regulate the used of this pesticide in the study areas.
\end{abstract}

Keywords: Organophosphorus, Pesticide, Vegetables, Soil, Pollution, Agriculture

\section{Introduction}

Pests contribute significantly to food losses and the control of pests is very central to the attainment of food security at all spatial [1]. Pesticides are extensively used in agricultural production to check or control pests, diseases weeds and other plant pathogens in an effort to reduce or eliminate yield losses and preserve high product quality [2]. Although pesticides are manufactured under very strict regulation processes to function with logical certainty and minimal impact on human health and the environment, serious concerns have been raised about health risks resulting from residues in food $[2,3]$. By their very nature, most pesticides show a high degree of toxicity because they are intended to kill certain organisms and thus create some risk of harm [4,5]. Within this framework, pesticide use has evoked grave concerns not only of potential effects on human health but also about impacts on wildlife and sensitive ecosystems $[3,6]$.

Wrong application techniques, badly maintained or totally unsuitable spraying equipment and inadequate storage practices exacerbate these risks [7]. Often, the reuse of old pesticide containers for food and water storage also contributes to the risk of exposure [3, 8]. But pesticide residues in plants may be unavoidable even when pesticides are used in accordance with good agriculture practices [1]. This is because researches conducted for the past decade in Ghana and internationally point to the presence of pesticide residues in a number of food items, such as strawberries, onions, cucumber, lettuce, cabbage, okra, pepper, tomatoes, beans, oranges and lemons [9]. In addition, pesticide residues constitute a danger to soil microfauna and microflora [10], and their toxic effects manifest on humans when bioaccumulation occurs along the food chain after initial plant uptake.

Intensive agricultural practices have often included the 
use of pesticides to enhance crop yields, but the improvement in yield is sometimes concomitant with the occurrence and persistence of pesticide residues in soil and water [11]. Pesticides may reach the soil through direct application to the soil surface, incorporation in the top few inches of soil, or during application to crops. Pesticides can also enter ground water resources and surface run-off during rainfall, thereby contributing to the risk of environmental contamination. The fate of pesticides in soil and water environments is influenced by the physicochemical properties of the pesticide, the properties of the soil and water systems (including the presence of clay materials, organic matter, $\mathrm{pH})$, climate, biology, and other factors [11].

Plant root uptake of persistent residues is a common form of plant contamination. The quantity of pesticides absorbed by a given plant generally depends upon the water solubility of the pesticide, the quantity of pesticide within the soil and the organic matter content of the soil. The total amount absorbed by a single plant increases with time if the residue is persistent. For non-polar pesticides, soil organic matter is the most important soil factor influencing the sorption of residues. The hazard posed by the pesticide residues in the plant depends on the toxicity of the residue, the ability of the plant to metabolize or eliminate the residue before it is harvested and the translocation of the residue to the harvested portions of the plant. Non-phytotoxic residues in the plant pose a greater threat to the consumers than the phytotoxic one, because the latter type makes the plant sick and identifiable. Plants with non-phytotoxic residues cannot be identified and excluded from harvesting. The level of contamination of plants and agricultural produce is associated with the intensity of usage of pesticides on farms. Government and private laboratories around the world have monitor the levels of pesticide residues in imported and locally grown agricultural produce and varying levels of pesticide residues have been reported in the produce [12]. Significantly high quantities of pesticide residues have been reported in vegetables and fruits, staple diets such as rice [13, 14], wheat [15]. Insecticides have been identified in tomatoes [16, 17] onion [18], potatoes [19]. Pesticide residues have been identified in oranges [20] and apples [21] in excessive amounts. Food chain contamination lipid soluble and persistent pesticides accumulate in living organisms from bacteria to algae to higher plants and animals including man. Bioaccumulation of a contaminant occurs within each organism and within each food chain. In the grazing food chain, the lipophilic contaminants pass on from herbivores to carnivores and in the detritus food chain from dead organic matter into microorganisms and then to detritus-feeding organisms and their predators. Each time a lower food chain organism is consumed by a higher food chain organism the pesticide residues will largely be retained by the consuming organism. Food chains are not isolated sequences but interlock with each other and form a food web. As the position of an organism in the food web increases, the pesticide residue concentration in that organism increases.
Alau Dam and Gongulong are primarily agriculture areas with intense pesticide usage. Pesticides are extensively used in the area to enhance the production of vegetables, cereals and fruits, as well as the control of vector-borne diseases for public health. Vegetables from the Alau Dam and Gongulong agricultural areas also constitute an important source of vitamins for the inhabitants in and around the Metropolis, and are a major source of income for the inhabitants. However, the agricultural activities have impacted negatively on the soil because bioaccumulation and bioconcentration of the pesticides in the vegetables are capable of reaching toxic levels even at low exposure. No studies have been carried out in Alau Dam and Gongulong agricultural areas despite the fact that pesticides of high toxicity are used through ground application on the vegetable farms.

\section{Materials and Methods}

\subsection{Study Area}

Vegetable and soil samples were collected from Alau Dam agricultural area within Jere local government andGongulongagricultural area in Konduga local government,Borno State, Nigeria. (Map 1).

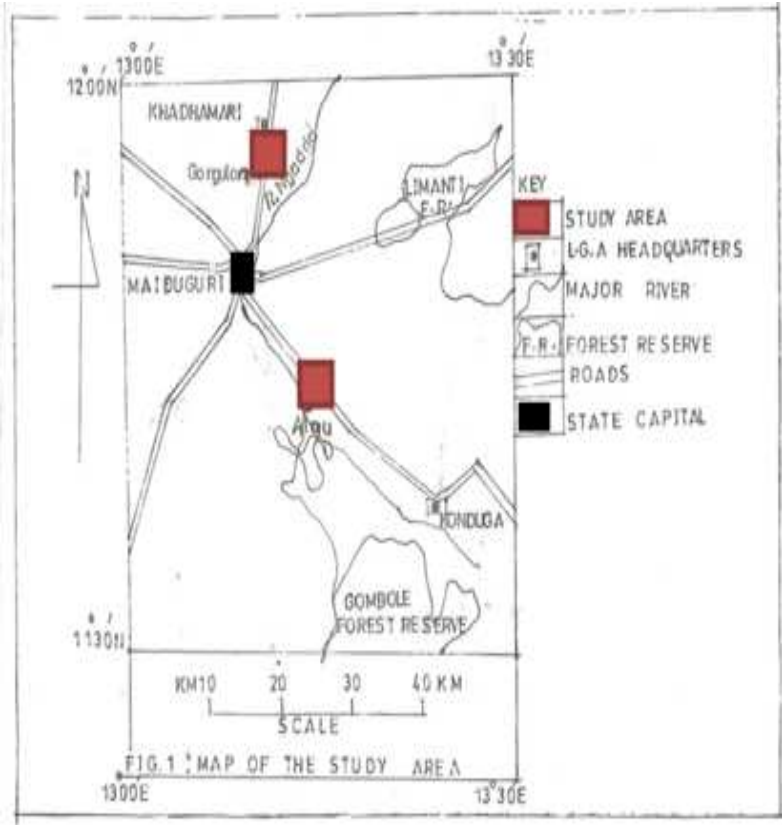

Map 1. Location of the Studied Areas

\subsection{Collection of Vegetable and Soil Samples}

At each sampling sites, $20 \mathrm{~g}$ each of the five vegetables namely, spinach, lettuce, cabbage, tomato and onion were also collected from three different locations in each area to provide replicate samples of each crop. The Vegetables samples were collected in clean polyethylene bag; labeled and transported to the laboratory and preserved in a refrigerator at $4 \mathrm{OC}$, pending extraction.

Soil samples were collected from ten plots, from Alau 
Dam and Gongulong Agricultural areas. In each plot, three soil samples were collected at three depths $(0-10 \mathrm{~cm}, 10$ $20 \mathrm{~cm}$ and $20-30 \mathrm{~cm})$, using spiral auger of $2.5 \mathrm{~cm}$ diameter. The Soil samples were then randomly selected and bulked together to form a composite sample before being placed in clean plastic bags and transported to Chemistry laboratory University of Maiduguri.

\subsection{Extraction of Vegetable Samples}

The method of extraction used for the vegetables was the USEPA method 3510 for extracting pesticide residues in non-fatty crops, using ethyl acetate as the solvent. Sodium hydrogen carbonate $\left(\mathrm{NaHCO}_{3}\right)$ was used to neutralize any acid that may be present and the vegetable samples were washed thoroughly with distilled water. Twenty grams (20g) of each of the samples was placed in a mortar and anhydrous sodium sulphate $\left(\mathrm{Na}_{2} \mathrm{SO}_{4}\right)$ was used to remove water from the sample matrix. After weighing, the samples were washed thoroughly with distilled water and placed in a mortar and ground to a paste using a pestle. The paste was transferred into a conical flask with the help of a spatula and $40 \mathrm{ml}$ of Ethyl acetate was added and shaken thoroughly. A $5 \mathrm{~g}$ portion of sodium hydrogen carbonate $\left(\mathrm{NaHCO}_{3}\right)$ was added to the mixture followed by $20 \mathrm{~g}$ of anhydrous sodium sulphate $\left(\mathrm{Na}_{2} \mathrm{SO}_{4}\right)$ and the entire mixture was shaken vigorously for one hour. This process was to ensure that enough of the pesticide residue dissolved in the ethyl acetate. The procedure was repeated for the samples from each area and the mixture was filtered into a labeled container before being centrifuged at a speed of $1800 \mathrm{rpm}$ for 5 mins. The organic layer was decanted into a container and a 1:1 mixture of $5 \mathrm{ml}$ ethyl acetate and cyclohexane was added.

\subsection{Cleaning up of Vegetable Extracts}

The vegetable extracts were cleaned up as follows; A $10 \mathrm{~mm}$ chromatographic column was filled with $3 \mathrm{~g}$ activated silica gel and topped up with 2 to $3 \mathrm{~g}$ of anhydrous sodium sulphate, and $5 \mathrm{ml}$ of $\mathrm{n}$-hexane was added to the column. The residue in $2 \mathrm{ml} \mathrm{n}$-hexane was transferred onto the column and the extract was rinsed thrice with $2 \mathrm{ml}$ hexane. The procedure was repeated for all the samples. The sample was collected in a $2 \mathrm{ml}$ vial, sealed and placed in the refrigerator in the laboratory with temperature below normal room temperature, to prevent evaporation of the ethyl acetate.

\subsection{Extraction of Soil Sample}

The Soil samples were extracted using a soil-packed bulb column, and $25 \mathrm{~g}$ of each sample was weighed into a glass jar, and fortified at this step, before adding $25 \mathrm{~g}$ of pre-cleaned sand and $50 \mathrm{~g}$ of granular sodium sulfate. The sample mixture was manually shaken for 30 seconds, placed on a roller for 30 seconds, and then allowed to stand for 20 minutes to provide time for the sodium sulfate to adsorb any residual moisture from the soil. The sample mixture was then transferred to a $250 \mathrm{ml}$ bulb column and the sample jar was triple rinsed with small amounts of $5 \mathrm{ml}$ of hexane and transferred to the bulb column. The soil content was extracted with acetone:hexane $(1: 1 \mathrm{v} / \mathrm{v}, 250 \mathrm{ml})$ and the eluate collected and concentrated to $100 \mathrm{ml}$ using a rotary evaporator. The soil extract was then subjected to additional cleanup.

\subsection{Cleaning up of Soil Extracts}

The concentrated soil eluate was washed by liquid-liquid partitioning with saturated sodium sulfate $(25 \mathrm{ml})$ and distilled water $(300 \mathrm{ml})$ in a separatory funnel $(500 \mathrm{ml})$. After shaking, the aqueous layer was drained into a beaker and hexane was transferred to a separatory funnel $(250 \mathrm{ml})$. The aqueous layer was returned to the $500 \mathrm{ml}$ separatory funnel and re-extracted with $15 \%$ dichloromethane in hexane (40 $\mathrm{ml})$. The organic layer was combined in the $250 \mathrm{ml}$ separatory funnel and gently washed with distilled water $(100 \mathrm{ml})$ for about 30 seconds. After discarding the aqueous layer, the organic layer was filtered through sodium sulfate, evaporated to near dryness on a rotary evaporator; rinsed the sides of the flask with hexane $(20 \mathrm{ml})$, and evaporated to about $1 \mathrm{ml}$. The sample extract was quantitatively transferred to a centrifuge tube, concentrated on a nitrogen evaporator to $0.5 \mathrm{ml}$, and diluted to $2.0 \mathrm{ml}$ final volume in hexane prior to Gas chromatography analysis.

\subsection{Determination of Pesticide Residues}

The SHIMADZU GC/MS (GC - 17A), equipped with fluorescence detector was used for the chromatographic separation and was achieved by using a 35\% diphenyl, 65\% dimethyl polysiloxane column. The oven was programmed as follows: initial temperature $40 \mathrm{OC}, 1.5 \mathrm{~min}$, to $150 \mathrm{OC}$, $15.0 \mathrm{~min}, 5 \mathrm{OC} / \mathrm{min}$ to $200 \mathrm{OC}, 7.5 \mathrm{~min}, 25 \mathrm{OC} / \mathrm{min}$ to 290 OC with a final hold time of $12 \mathrm{~min}$ and a constant column flow rate of $1 \mathrm{ml} / \mathrm{min}$. The detection of pesticides was performed using the GC-ion trap MS with optional MSn mode. The scanning mode offer enhances selectivity over either full scan or selected ion monitoring (SIM). In SIM at the elution time of each pesticide, the ration of the intensity of matrix ions increase exponentially versus that of the pesticide ions as the concentration of the pesticide approach the detection limit, decrease the accuracy at lower levels. The GC-ion trap MS was operated in MSn mode and perform tandem MS function by injecting ions into the ion trap and destabilizing matrix ions, isolating only the pesticide ions. The retention time, peak area and peak height of the sample was compared with those of the standards for quantization.

\subsection{Data Handling}

Data collected were subjected to a one-way analysis of variance (ANOVA) and least significant Difference (LSD) to assess whether or not pesticide residues varied significantly within and between the vegetables and soil samples. The statistical significance tests were carried at 5\% confidence level $(\mathrm{p}<0.05)$. 


\section{Results}

\subsection{Organophosphate Pesticide Residues in Different Parts of Vegetable Samples from Alau Dam Agricul- tural Site}

Figure 1 presents the mean concentrations of some organophosphate pesticide residues (dichlorvos, diazinon, chlorpyrifos, and fenitrothion) in different parts of tomato and other vegetables from Alau Dam agricultural site. The levels of these pesticides in the root sample of tomato ranges between 4.54 and $23.53 \mu \mathrm{g} / \mathrm{g} ; 8.21$ and $78.71 \mu \mathrm{g} / \mathrm{g}$ Stem, 8.98 and $100.51 \mu \mathrm{g} / \mathrm{g}$ leaf and 10.08 and $121.91 \mu \mathrm{g} / \mathrm{g}$ fruit. The lowest concentration of $4.54 \mu \mathrm{g} / \mathrm{g}$ was observed in the root, while the highest concentration of $121.91 \mu \mathrm{g} / \mathrm{g}$ was observed in the fruit. For onion samples, the levels of these pesticides in root sample ranged between 11.2 and $59.08 \mu \mathrm{g} / \mathrm{g} ; 13.54$ and $131.04 \mu \mathrm{g} / \mathrm{g}$ Stem and 17.86 and $156 \mu \mathrm{g} / \mathrm{g}$ leaf. The lowest concentration of $11.2 \mu \mathrm{g} / \mathrm{g}$ was observed in the root, while the highest concentration of 156 $\mu \mathrm{g} / \mathrm{g}$ was observed in the leaf. The levels of organophos- phate pesticide residues (dichlorvos, diazinon, chlorpyrifos, and fenitrothion) in different parts of cabbage are presented in Figure 1 and ranged between 10.66 and $118.14 \mu \mathrm{g} / \mathrm{g}$ in root; 12.43 and $145.41 \mu \mathrm{g} / \mathrm{g}$ in Stem, and 15.76 and 161.25 $\mu \mathrm{g} / \mathrm{g}$ in leaf. The lowest concentration of $10.66 \mu \mathrm{g} / \mathrm{g}$ was observed in the root, while the highest concentration of $161.25 \mu \mathrm{g} / \mathrm{g}$ was observed in leaf. For lettuce samples as presented in Figure 1 the levels of this pesticide ranged between 11.65 and $127.41 \mu \mathrm{g} / \mathrm{g}$ root; 15.65 and $143.02 \mu \mathrm{g} / \mathrm{g}$ Stem and 19.65 and $163.17 \mu \mathrm{g} / \mathrm{g}$ leaf, The lowest concentration of $11.65 \mu \mathrm{g} / \mathrm{g}$ was observed in the root, while the highest concentration of $163.17 \mu \mathrm{g} / \mathrm{g}$ was observed in leaf. Similarly, concentrations of these pesticides residues in different parts of spinach are presented as follows. The levels of these pesticides in the root sample of spinach ranged between 9.31 and $79.21 \mu \mathrm{g} / \mathrm{g} ; 11.03$ and $93.72 \mu \mathrm{g} / \mathrm{g}$ Stem, and 15.71 and $131.63 \mu \mathrm{g} / \mathrm{g}$ leaf. The lowest concentration of $9.31 \mu \mathrm{g} / \mathrm{g}$ was observed in the root, while the highest concentration of $93.72 \mu \mathrm{g} / \mathrm{g}$ was observed in the leaf.

\section{- Dichlorvos $\|$ Diazinon $\|$ Chlorpyrifos $\|$ Fenitrothion}

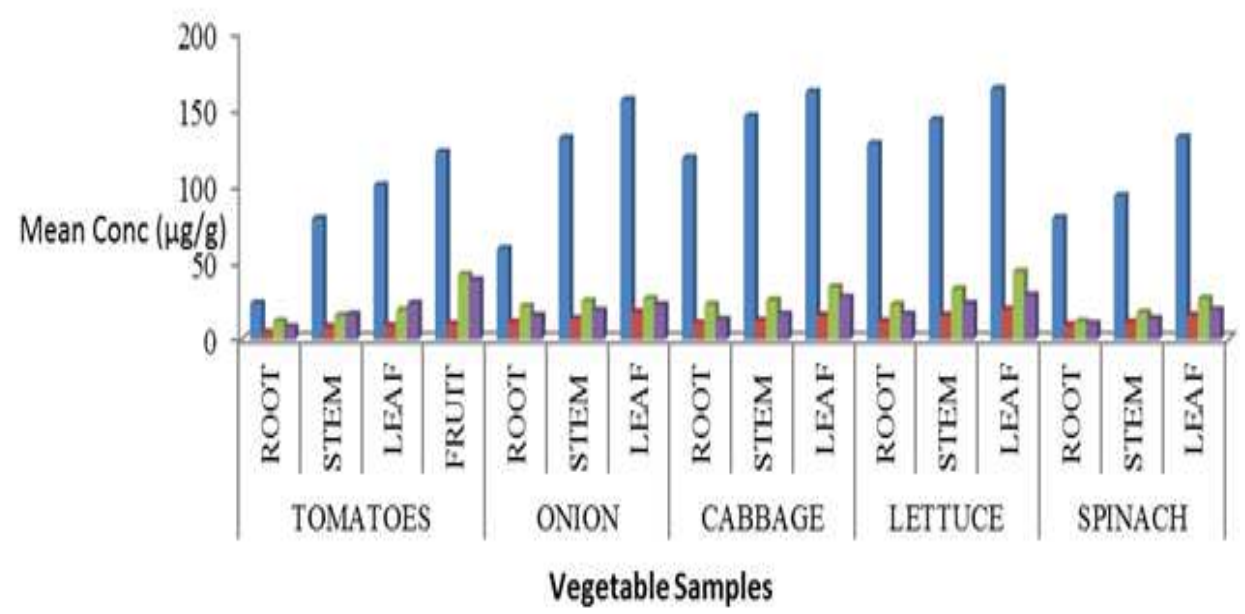

Figure 1. Mean concentrations of some Organophosphorus pesticide residues in different parts of Vegetable samples from Alau Dam Agricultural site

\subsection{Organophosphate Pesticide Residues in Different Parts Vegetable Samples from Gongulong Agricul- tural Site}

The mean concentrations of some of organophosphate pesticide residues (dichlorvos, diazinon, chlorpyrifos, and fenitrothion) in different parts of vegetables from Gongulong agricultural site are presented in Figure 2. The levels of these pesticides in the root sample of tomato ranges between 10.11 and $66.71 \mu \mathrm{g} / \mathrm{g} ; 13.86$ and $76.66 \mu \mathrm{g} / \mathrm{g}$ Stem, 16.98 and $88.37 \mu \mathrm{g} / \mathrm{g}$ leaf, and 20.65 and $119.48 \mu \mathrm{g} / \mathrm{g}$ fruit. The lowest concentration of $10.11 \mu \mathrm{g} / \mathrm{g}$ was observed in the root, while the highest concentration of $119.48 \mu \mathrm{g} / \mathrm{g}$ was observed in fruit. For onion samples the values of these pesticides ranged between 11.41 and $86.34 \mu \mathrm{g} / \mathrm{g}$ root; 16.87 and $97.23 \mu \mathrm{g} / \mathrm{g}$ Stem and 22.54 and $136.14 \mu \mathrm{g} / \mathrm{g}$ leaf. The lowest concentration of these pesticides was observed in the root, while the highest concentration was observed in leaf. Also, the organophosphate pesticide residues in different parts of cabbage as presented in Figure 2. Root concentrations ranged between 14.34 and $132.98 \mu \mathrm{g} / \mathrm{g} ; 17.87$ and $151.98 .71 \mu \mathrm{g} / \mathrm{g}$ Stem, and 23.99 and $168.92 \mu \mathrm{g} / \mathrm{g}$ leaf. The mean concentration of some of organophosphate pesticide residues in different parts of lettuce is presented as follows, the levels of these pesticides in the root sample of lettuce ranges from 15.23 and $136.45 \mu \mathrm{g} / \mathrm{g} ; 20.42$ and $148.8 \mu \mathrm{g} / \mathrm{g}$ Stem and 23.98 and $175.43 \mu \mathrm{g} / \mathrm{g}$ leaf. The highest concentration of $175.43 \mu \mathrm{g} / \mathrm{g}$ was observed in the leaf, while the lowest concentration of $15.23 \mu \mathrm{g} / \mathrm{g}$ was observed in the leaf. For spinach samples as presented in Fig- 
ure 2. The levels of these pesticides in the root sample of spinach ranged from 10.11 to $116.05 \mu \mathrm{g} / \mathrm{g} ; 15.34$ to 150.05 $\mu \mathrm{g} / \mathrm{g}$ Stem and 18.93 to $176.56 \mu \mathrm{g} / \mathrm{g}$ leaf. The lowest con- centration of these pesticides of $10.11 \mu \mathrm{g} / \mathrm{g}$ was observed in the root, while the highest concentration of $176.56 \mu \mathrm{g} / \mathrm{g}$ was observed in leaf.

$$
\text { =Dichlorvos } \quad \text { Diazinon } \quad \text { Chlorpyrifos Fenitrothion }
$$

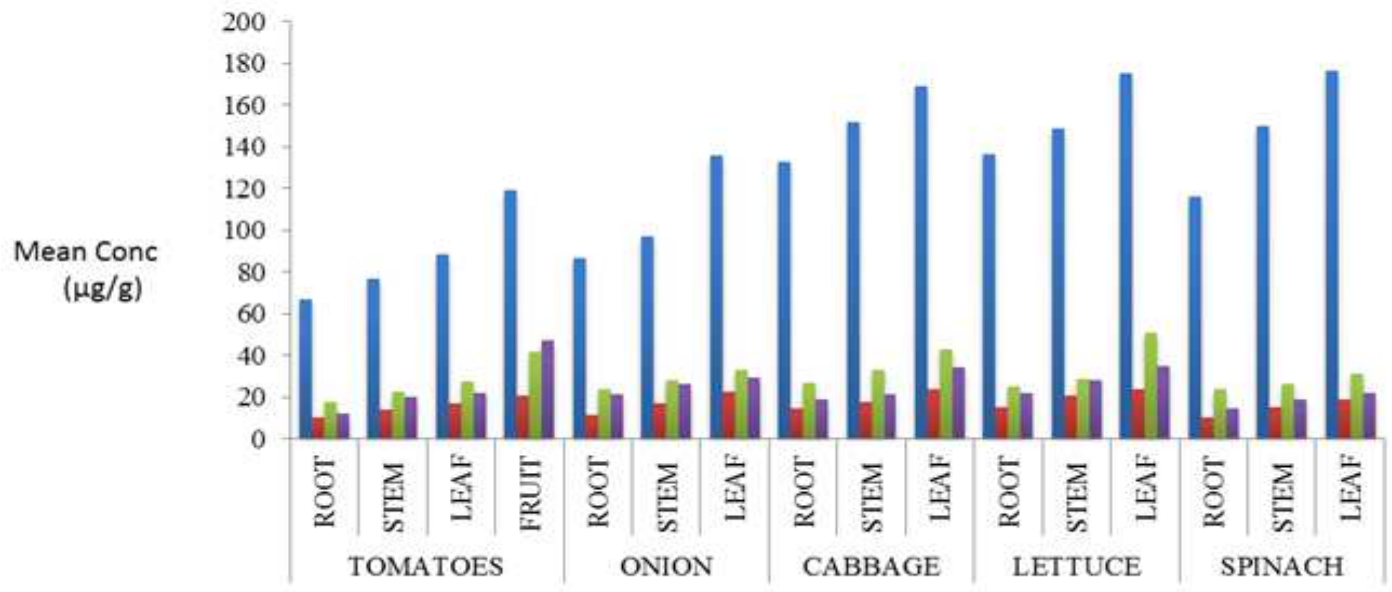

\section{Vegetable Samples}

Figure 2. Mean concentrations of some Organophosphorus pesticide residues in different parts of Vegetable samples from Gongulong Agricultural site .

\subsection{Organophosphate Pesticide Residues in Soil Samples from Different depth at Alau Dam and Gongulong Agricultural Site}

The concentrations of some organophosphate pesticide residues (dichlorvos, diazinon, chlorpyrifos, and fenitrothion) in different depth of soil sample from Alau Dam agricultural site are presented in Figure 3. The levels of these pesticides for $0-10 \mathrm{~cm}$ depth ranged from 57.98 to $232.98 \mu \mathrm{g} / \mathrm{g}, 78.92$ to $264.98 \mu \mathrm{g} / \mathrm{g}$ at $11-20 \mathrm{~cm}$ depth, and 88.98 to $287.89 \mu \mathrm{g} / \mathrm{g}$ at $21-30 \mathrm{~cm}$ depth. The lowest value of $57.98 \mu \mathrm{g} / \mathrm{g}$ was observed at depth $0-10 \mathrm{~cm}$, while the highest concentration of $287.89 \mu \mathrm{g} / \mathrm{g}$ was observed at depth $21-30 \mathrm{~cm}$.

Figure 4 present the mean concentrations of some of organophosphate pesticide residues (Dichlorvos, Diazinon, Chlorpyrifos, and Fenitrothion) from different depth of soil sample from Gongolong agricultural site. The levels of these pesticides at depth $0-10 \mathrm{~cm}$ ranged from 65.87 to $211.03 \mu \mathrm{g} / \mathrm{g} ; 82.45$ to $232.34 \mu \mathrm{g} / \mathrm{g}$ at $11-20 \mathrm{~cm}$ depth and 104.98 to $267.18 \mu \mathrm{g} / \mathrm{g}$ at $21-30 \mathrm{~cm}$ depth. The highest value of $267.18 \mu \mathrm{g} / \mathrm{g}$ was observed at depth of $21-30 \mathrm{~cm}$, while the lowest concentration of $65.87 \mu \mathrm{g} / \mathrm{g}$ was observed at depth of $0-10 \mathrm{~cm}$ soil sample.

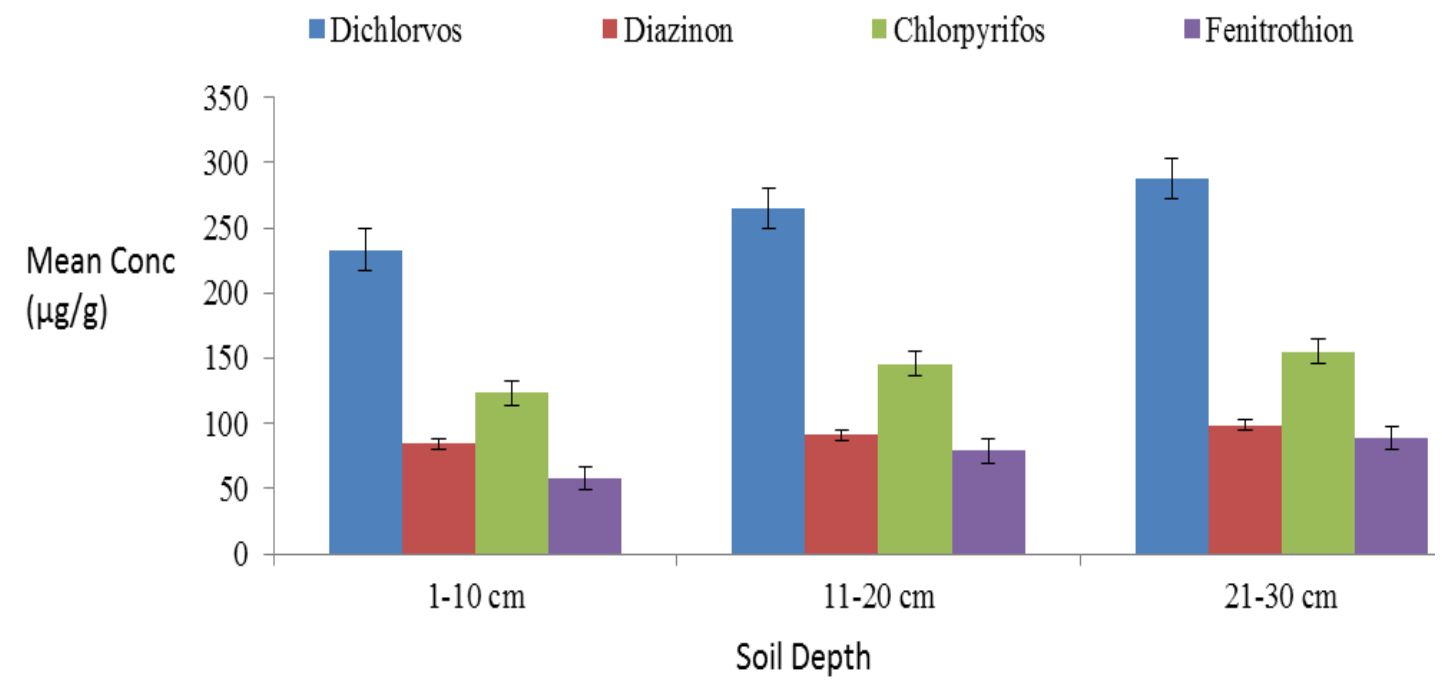

Figure 3: Concentrations of some Organophosphorus pesticide residues in Soil scomples from Alau Dam Agricultural site 


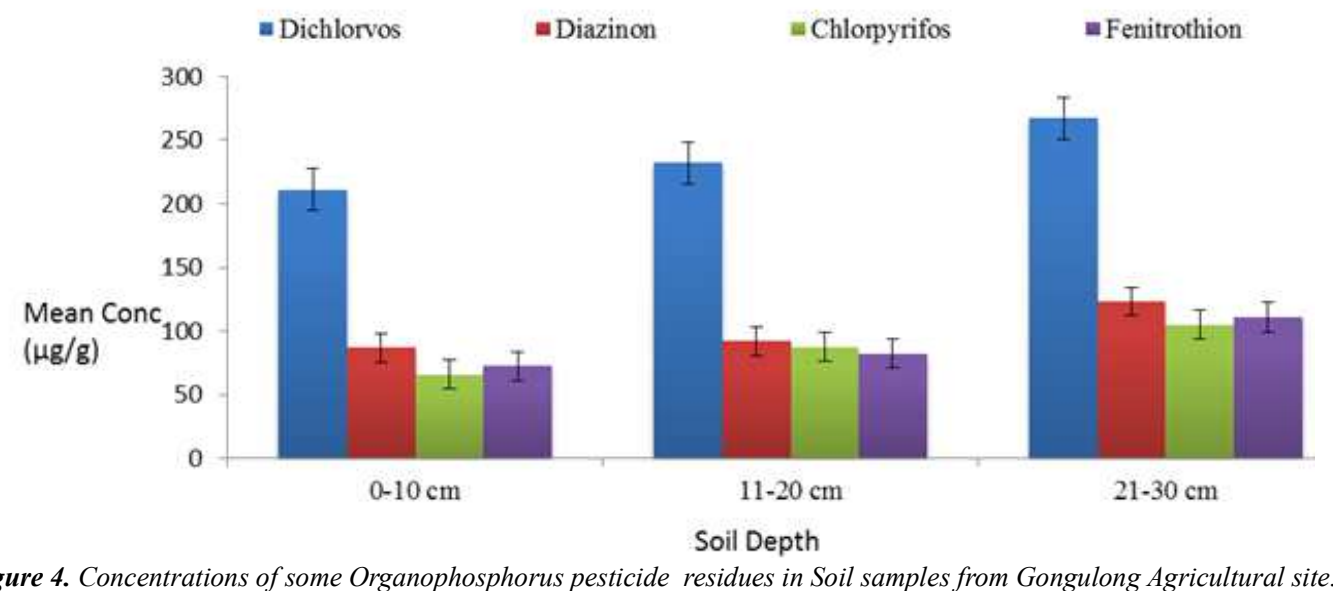

\section{Discussion}

In Alau Dam and Gongulong agricultural areas, the concentrations of organophosphate pesticide residues (dichlorvos, diazinon, chlorpyrifos, and fenitrothion,) were detected in all the samples. The highest concentration of $163.17 \mu \mathrm{g} / \mathrm{g}$ (dichlorvos) was observed in the leaf of lettuce in Figure 1, while the lowest concentration was that of diazinon which was observed in the root of tomatoes with a value of $8.98 \mu \mathrm{g} / \mathrm{g}$ (see Figure 1). For Gongulong agricultural site, the concentrations of organophosphate pesticide residues (dichlorvos, diazinon, chlorpyrifos, fenitrothion) were also detected in all the samples. The highest concentration of $175.43 \mu \mathrm{g} / \mathrm{g}$ (dichlovos) was observed in the leaf of lettuce (see Figure 2), while the lowest concentration was that of diazinonand was observed in the root of tomatoes with a value of $10.11 \mu \mathrm{g} / \mathrm{g}$ (see Figure 2). These results signify that lettuce is a better accumulator of pesticides than the other vegetables analyzed. The values of dichlorvos detected in all the vegetable samples were relatively much higher than those of diazinon, chlorpyrifos, and fenitrothion. The levels of diazinon, chlorpyrifos, fenitrothion detected in all the samples from the two agricultural sites were above the EU set maximum residue limit (MRL) of $0.04 \mu \mathrm{g} / \mathrm{g}$ for diazinon, $0.30 \mu \mathrm{g} / \mathrm{g}$ for chlorpyrifos and 0.0 $1 \mu \mathrm{g} / \mathrm{g}$ forfenitrothion. The Acceptable Daily Intake values (ADIs) of diazinon, chlorpyrifos, fenitrothion for vegetables are $0.0002 \mu \mathrm{g} / \mathrm{g}, 0.01 \mu \mathrm{g} / \mathrm{g}$ and $0.005 \mu \mathrm{g} / \mathrm{g}$ respectively. The results obtained from the present study exceeded this Acceptable Daily Intake values and this may be attributed to the common use of this pesticide for pest control in the study area.

At the Alau Dam and Gongulong agricultural sites, the concentration of organophosphate pesticide residues dichlorvos, diazinon, chlorpyrifos, and fenitrothion were detected in all the soil samples. The highest concentration was that of dichlovos $(289.89 \mu \mathrm{g} / \mathrm{g})$ which was observed at the depth of 21-30 cm, while Fenitrothion showed the lowest concentration of $57.98 \mu \mathrm{g} / \mathrm{g}$ at the depth of $0-10 \mathrm{~cm}$ in the Alau Dam Agricultural area. For Gongulong agricultural area, the highest pesticide residue concentration of Dichlovos which was observed at the depth of $21-30 \mathrm{~cm}$, with value of $267.18 \mu \mathrm{g} / \mathrm{g}$, while Fenitrothion showed the lowest concentration of $72.34 \mu \mathrm{g} / \mathrm{g}$ at the depth of $0-10 \mathrm{~cm}$. The most serious concern relating to the organophosphate is that they are still suspected to have serious toxicological impact upon terrestrial wildlife and man [23]. A similar observation was also reported by [24] in another study in Lake Naivasha catchment, an indication that most of the pesticides being used are harmful to the environment. It could also indicate lack of regulation program in a country [25]. The implications of high pesticides residue include muscle cell degeneration, which involves the respiratory muscles. Chronic exposure to organophosphate might damage the peripheral nervous system, and the patient's behavioural abilities and/or personality, chronic fatigue syndrome and effects on the heart. Sheep dip farmers have been identified to report exhaustion, long term fatigue, memory loss and confusion. However, the concentrations of all the organophosphate pesticide residues in the soil samples from the two agricultural areas were above the EU set maximum residue limits (MRLs) of $0.04 \mu \mathrm{g} / \mathrm{kg}$ for diazinon, $0.30 \mu \mathrm{g} / \mathrm{kg}$ for chlorpyrifos, and $0.01 \mu \mathrm{g} / \mathrm{kg}$ for fenithrothion. The high concentrations of these pesticides in soils than MRL could result to toxic effect on man and animal that depends on vegetables from such soil as food.

\section{Conclusion}

Organophosphorus pesticide residues were detected in all the vegetable and soil samples collected from Alau Dam and Gongulong agricultural areas. The concentrations of all the pesticides were observed to be higher in the leaf of all the vegetable samples studied, while the root had the lowest concentrations in the study areas. The concentrations of all the pesticides in the soil samples were observed to be higher at the depth of $21-30 \mathrm{~cm}$, while the lowest concentrations were observed at the depth of $0-10 \mathrm{~cm}$. The concentrations of all the pesticides in the vegetables and soil samples from the two agricultural areas were much higher than the European Union (EU) set maximum residue limits (MRLs) 
and acceptable daily intake values (ADIs) set for vegetables and soil by the European Union (EU). Based on the results of this study, Government should enforced routine monitoring of pesticide residues in these study areas so as to prevent, control and reduces environmental pollution. The farmers and the inhabitants of the study areas should be educated on the dangers of pesticides for pest control.

\section{References}

[1] Iya, I.B. and Kwaghe, T.T. (2007). The economic effect of spray pesticides on cowpea (Vignaunguculata L. Walp.) production in adamawa state of Nigeria. Int. J.Agric. Res., 2: 647-650.

[2] Eskenazi, B., Rosas, L.G., Marks, A.R., Bradman A and. Harley, K. (2008). Pesticide toxicity and the developing brain.Basic Clin.Pharmacol.Toxicol., 102: 228-236.

[3] Damalas, C.A and Eleftherohorinos, I.G. (2011). Pesticide exposure, safety issues and risk assessment indicators. Int. $J$. Environ. Res. Public Health, 8: 1402-1419.

[4] Abdelgadirand, E.H. and Adam, S.E.I. (2011). Effect of various levels of dietary malathion on wistar rats. J. Pharmacol. Toxicol., 6: 69-75.

[5] Zidan, N.E. (2009). Evaluation of the reproductive toxicity of chlorpyrifos methyl, diazinon and profenofos pesticides in male rats. Int. J. Pharmacol., 5: 51-57.

[6] Power, A.G. 2010. Ecosystem services and agriculture: Tradeoffs and synergies. Philos Trans. R Soc. Lond. B Biol. Sci., 365: 2959-2971.

[7] Al-Wabel, M.I., El-Saeid, M.H., Al-Turki, A.M and AbdelNasser, G. (2011). Monitoring of pesticide residues in Saudi Arabia agricultural soils. Res. J. Environ. Sci., 5: 269-278.

[8] Ecobichon, D.J. (2001). Pesticide use in developing countries.Toxicology, 160: 27-33.

[9] Hanson, R., Dodoo, D.K andEssumang, D.K. (2007). The effect of some selected pesticides on the growth and reproduction of fresh water oreochromisniloticus, chrysicthysnigrodigitatus and clariasgriepings. Bull. Environ. Contam.Toxicol., 79: 544-547.

[10] Pal, R., Chakrabarti, K., Chakraborty, A and Chowdhury, A. (2006). Degradation and effects of pesticides on soil microbiological parameters-A review.Int. J. Agric. Res., 1: 240258.

[11] Ware G, W, Whitacre, D, M, (2004). The pesticide book meister pro information resources, willougbyohiopp 496.
[12] Dogenheim, S.M., Alla, S.A.G., ElSyes, S.M.A., Al Maz, M.M and SalamaE.Y. (1996a). Organochlorine and organophophorus pesticide residues in food from Egyptian local markets J, A,OA,C INT, 79(4); 949-952.

[13] Menzer, R.E and Thomas, E.D. (1970). Dimethoate residues in winter spinach.J EconEntomol,; 63(1): 311-312.

[14] Miyata, M., Kamakura, K., Narita, M., Hirahara, Y., Okamoto, K., Hasegawa, M., Koiguchi, S., Miyoshi, T., Yamana, T., andTonogai, Y. (1994). Studies on systematic determination of organophosphrus, carbamate, organochlorine and pyrethroid pesticides in polished rice by gas chromatography. $J$ Food HygSoc Japan,; 35(3): 276-286.

[15] Chow, C., Montgomery, M.L and Yu, T.C. (1971). Methodology and analysis for residues of Courtney KD, Andrews JE, Springer J, Dailey L. Teratogenic evaluation of the MCP and 2,4,5-7 in wheat. Bull Environ ContamToxicol, 6(6): $575-580$.

[16] Hughes, J.T, Tate, K.G and Wilson, P.D. (1969). Azinophosethyl residue on field grown tomatoes.New Zealand J Agric Res,; 12(2): 417-442.

[17] Galera, M.M., Vidal, J.L.M, Gonzalez, F.J.E and Garcia, M.D.G. (1997). A study of fenpropathrin residues in tomatoes and green beans grown in greenhouses in Spain.Pesticide Sci,; 50(2): 127-134.

[18] Wiersma, G.B., Mitchell, W.G and Stanford, C. L. (1972). Pesticide residues in onion and soil-.PesticMonit $J, 1972$; 5(4): 345-347.

[19] Gorbach, S and Wager, U. (1967). Pentachlorobenzene residues in potatoes.J Agric FoodChem,; 15(4): 654-656.

[20] Cabras, P., Angioni, A., Garau, V.L., Melis, M., Pirsi, F.M.,Karim, M and Minelli E.V. (1997). Persistence of insecticide residues in olives and olive oil. J Agri FoodChem,;

[21] Roy, S., Kumar, R., Roy, S and Sharma C.B. (1997). Biodegradation of fenitrothion in soil.Biomed Chromatogr; 10(2): 60-64.

[22] Barlas, N. (1999). Determination of Organochlorine pesticide residues in water and sediment samples in inner Anatolia in Turkey. Bull. Environ. Contam.Toxicol., 69: 236-242.

[23] Gitau, S. M. (1994). Organochlorine and Organophosphorus pesticide concentrations in water, sediment, and selected organisms in Lake Naivasha (Kenya). MSc. Thesis, Department of Chemistry, University of Moi, Eldoret, Kenya, p. 78

[24] Abuodha, J.O.Z and Hecky, C.O. (2005). Lake Victoria environment report on water quality and ecosystem status: Winum Gulf and River Basins in Kenya, p. 124. 